\title{
Cross Sphere Electrode Reaction: the Case of Hydroxyl Desorption during the Oxygen Reduction Reaction on Pt(111) in Alkaline Media
}

\author{
Yuke $\mathrm{Li}^{1}$ and Zhi-Feng Liu ${ }^{*, 1,2}$ \\ ${ }^{I}$ Department of Chemistry and Centre for Scientific Modeling and Computation, Chinese \\ University of Hong Kong, Shatin, Hong Kong, China \\ ${ }^{2}$ CUHK Shenzhen Research Institute, No.10, $2^{\text {nd }}$ Yuexing Road, Nanshan District, Shenzhen, China
}

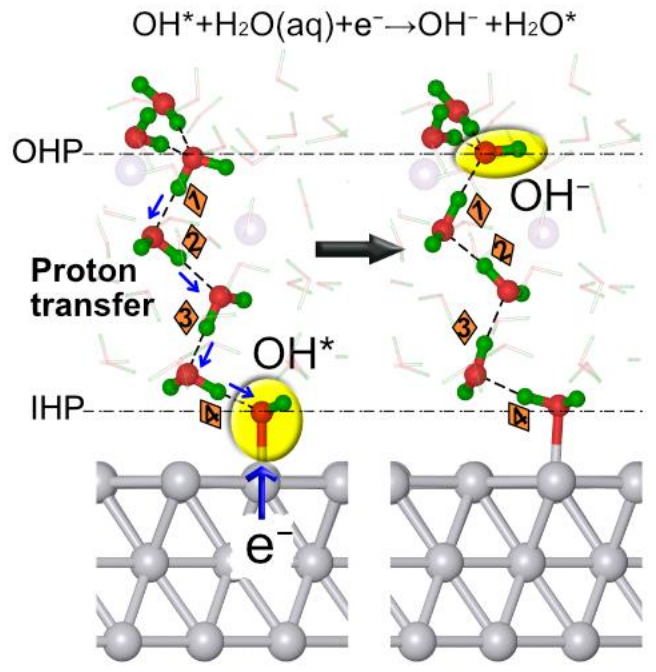

\begin{abstract}
Hydroxide ion is a common electrolyte when electrode reactions take place in alkaline media. In the case of oxygen reduction reaction on $\operatorname{Pt}(111)$, we demonstrate by ab initio molecular dynamics calculations, that the desorption of hydroxyl $\left(\mathrm{OH}^{*}\right)$ from the electrode surface to form a solvated $\mathrm{OH}^{-}$is a cross sphere process, with the reactant $\mathrm{OH}^{*}$ in the inner sphere and the product $\mathrm{OH}^{-}$directly generated in the aqueous outer sphere. Such a mechanism is distinct from the typical inner sphere and outer sphere reactions. It is dictated by the strong hydrogen bonding interactions between a hydroxide ion and water molecules and facilitated by proton transfer through solvation layers. It should play a significant role whenever $\mathrm{OH}^{*}$ desorption, or its reverse, $\mathrm{OH}^{-}$adsorption, is involved in an electrochemical reaction.
\end{abstract}

*E-mail: zfliu@cuhk.edu.hk (Z.F.L.). 


\section{Introduction}

An electrochemical process takes place in the interfacial region around an electrode immersed in a liquid with various solvated electrolytes. It's usually divided into two types. ${ }^{1,2}$ The first type is the inner sphere reaction, which proceeds on the electrode surface. Chemical bonds are often altered upon surface adsorption, which can catalyze reactions between adsorbed species. ${ }^{2,3}$ The reaction rate is strongly dependent on the surface structure and the electrode material. The second type is the outer sphere reaction, which proceeds in the liquid double layer in contact with the electrode surface. ${ }^{4-6}$ Reactants and products are solvated by solvent (typically water) molecules and not much affected by either the electrode surface or the adsorbed species. The charge transfer between the electrode and solvated reactants is achieved by electron tunneling, and the reaction rate is insensitive to the electrode material.

The oxygen reduction reaction on platinum electrode is a well-known model problem in electrochemistry, for understanding the reaction mechanism involving multiple electron transfers and several elementary steps and for improving the efficiency bottleneck in the operation of fuel cells. ${ }^{3,7-9}$ With the progresses in the development of alkaline membrane, ORR in alkaline media has attracted increasing attention in recent years, with its promises for using electrodes made of non-noble metals. ${ }^{10,11}$ Its mechanism also poses a fundamental challenge to the conceptual distinction between the inner and outer sphere electrode reactions.

As demonstrated in recent experiments, ${ }^{12-15}$ the ORR rate on $\operatorname{Pt}(111)$ depends on the identity of the cation $\mathrm{M}^{+}$, which comes from the alkali $\mathrm{MOH}$. The activity follows the order $\mathrm{Cs}^{+}>\mathrm{K}^{+}>$ $\mathrm{Na}^{+}>\mathrm{Li}^{+}\left(\right.$or $\left.\mathrm{Ba}^{2+}\right)$. While it clearly indicates the influence of solvated cations in the outer sphere, such an effect is not observed for ORR on $\mathrm{Au}(111),{ }^{13}$ pointing to the importance of the inner sphere factors as well. Furthermore, similar cation effects are also observed in other electrochemical processes, such as hydrogen oxidation, ${ }^{12,16}$ alcohol oxidation, ${ }^{17}$ and $\mathrm{CO}_{2}$ reduction. ${ }^{15,18}$ While being quite distinct from ORR, all these reactions take place in alkaline media.

The stabilization of adsorbed hydroxyl, $\mathrm{OH}^{*}$ (with * indicating surface adsorption in the following text), by solvated cations, are often offered as the explanation for such cation effects. The stabilization energy by $\mathrm{Li}^{+}$is found to be $0.1 \sim 0.15 \mathrm{eV}$ more than that by $\mathrm{Cs}^{+}$, according to density functional theory (DFT) calculations, which is suggested to be responsible for the reduced ORR activity in LiOH solution. ${ }^{12}$ However, recent DFT calculations with more extensive solvation of the cation flip the ordering of the stabilization energy, only $0.3 \mathrm{eV}$ for $\mathrm{Li}^{+}$, but $0.4 \mathrm{eV}$ for $\mathrm{K}^{+} .{ }^{19}$ 
Only when entropy effects are taken into consideration by ab initio molecular dynamics (AIMD) simulations, $\mathrm{Li}^{+}$would stabilize $\mathrm{OH}^{*}$ by $0.1 \mathrm{eV}$, while $\mathrm{K}^{+}$would destabilize $\mathrm{OH}^{*}$ by $0.1 \mathrm{eV}$. With a reported error in the calculated free energy being about $0.1 \mathrm{eV},{ }^{19}$ such small differences are more in line with the expected weak interactions between solvated cations and adsorbed species than proving conclusively the variation in interaction energy as being responsible for the observed cation effects. Furthermore, there are also experimental evidences that the cation effects could be due to the stabilization of negatively charged intermediates, rather than of $\mathrm{OH}^{*} .{ }^{20}$

As a model problem, ORR has been the subject of many theoretical studies, most of which have been aimed at understanding the mechanisms in acid media. ${ }^{7,21-32}$ Recent studies have highlighted the importance of solvation effects, ${ }^{33-35}$ and especially the dynamic treatment of explicitly solvated proton. ${ }^{36-38}$ In contrast, the ORR mechanism in alkaline media has received only limited attention, with kinetic models built upon adsorption energies and barriers obtained by static optimization. ${ }^{39}$

In this study, we apply AIMD simulations to explore the reaction channels underlying the ORR on Pt(111) in alkaline media, by explicitly modeling the $\mathrm{OH}^{-}$solvation and the variation in both the electrode potential and the cation concentration. The cation effect is thus treated as part of the overall ORR mechanism, rather than a stand-alone stabilization effect. Our results show that $\mathrm{OH}^{*}$ desorption is the key to understand the electrochemical measurements, including not only the origin of the large onset overpotential, the polarization curve in the high electrode potential region, ${ }^{40-42}$ and the irreversible feature in the oxide region of the cyclic voltammogram, ${ }^{41,43-45}$ but also the cation effects. More importantly, rather than a typical inner sphere or outer sphere electrode reaction, $\mathrm{OH}^{*}$ desorption actually involves both inner and outer spheres at the same time. It's a distinct type of cross sphere electrode reaction that could play an important role in many electrochemical processes in alkaline media.

\section{Results and Discussions}

\section{$\mathrm{O}_{2} *$ dissociation}

Our initial model includes a $\mathrm{NaOH}$, solvated by 42 water molecules, in contact with a slab of $\operatorname{Pt}(111)$ and a vacuum layer of $15.0 \AA$. Extensive solvation is essential to model reactions involving hydrated $\mathrm{OH}^{-}$. The electron detachment energy for an isolated $\mathrm{OH}^{-}$is only $1.8 \mathrm{eV},{ }^{46}$ compared to the work function of $5.7 \mathrm{eV}$ for $\mathrm{Pt}^{47}$. Without the presence of water molecules, an $\mathrm{OH}^{*}$ desorbed 
from $\mathrm{Pt}(111)$ would not be an $\mathrm{OH}^{-}$even after adding an extra charge to the slab. ${ }^{48}$ However, when $\mathrm{OH}^{-}$is hydrated, its electron detachment energy increases to $\sim 6 \mathrm{eV}$ in $\mathrm{OH}^{-}\left(\mathrm{H}_{2} \mathrm{O}\right)_{n}$ clusters by $n=7,{ }^{49}$ and further to $9.2 \mathrm{eV}$ in aqueous solution. ${ }^{50}$
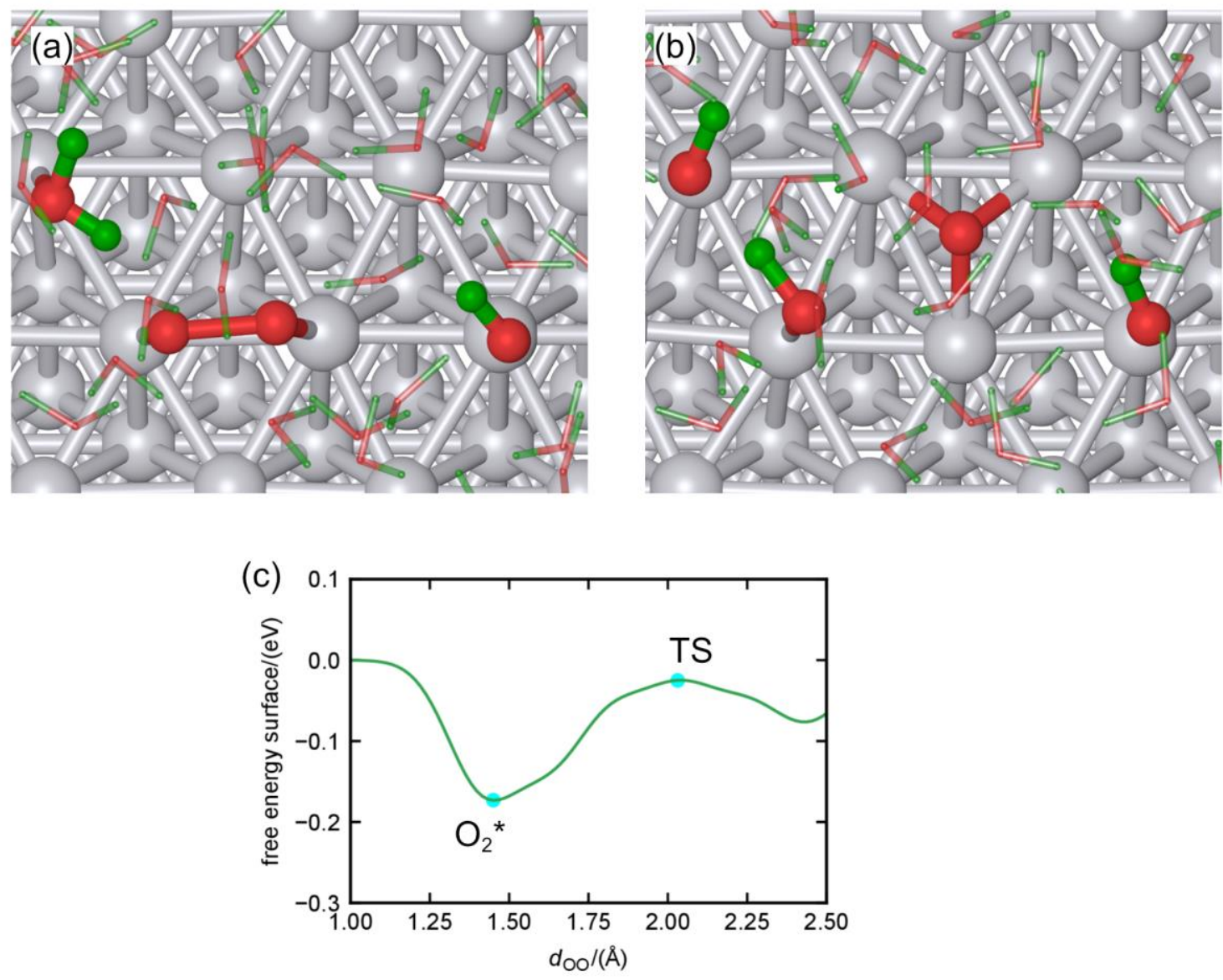

Figure 1: $\mathrm{O}_{2}$ dissociation on the $\mathrm{Pt}(111)$. (a) the reactant $\mathrm{O}_{2} *$, (b) the product $\mathrm{O}^{*}$ and $2 \mathrm{OH}^{*}$, (c) the free energy surface obtained by a MTD simulation with $d_{o o}$ as the reaction coordinate. The Pt, $\mathrm{O}$, and $\mathrm{H}$ atoms are shown in grey, red and green respectively. Water molecules in the solution layer are represented by stick models. As our main interest is in the dissociation barrier, the MTD simulation is stopped shortly after $\mathrm{O}_{2} *$ dissociation. The free energy of the dissociation product is therefore overestimated and the overall dissociation is actually exergonic.

During our AIMD simulations, the $\mathrm{NaOH}$ goes through ionic dissociation after the start of the equilibration run, and the solvated $\mathrm{OH}^{-}$soon finds its way to $\mathrm{Pt}(111)$ where it becomes $\mathrm{OH}^{*}$, while $\mathrm{Na}^{+}$stays solvated in the liquid layer. $\mathrm{An}_{2}$ molecule is then introduced into the model, and 
after equilibration, it is chemisorbed on $\mathrm{Pt}(111)$ on two adjacent top sites, as shown in Figure 1. With the $\mathrm{O}-\mathrm{O}$ distance, $d_{o o}$, as the reaction coordinate, the free energy profile for $\mathrm{O}_{2}{ }^{*}$ dissociation is sampled by meta-dynamics method (MTD) by over 15 separate MTD runs (See Figure S1 and Table S1 in the Supplementary Materials). When the O atoms are well solvated, the dissociation barrier averages $\sim 0.2 \mathrm{eV}$, with a fluctuation of $\sim 0.1 \mathrm{eV}$. One of the $\mathrm{O}$ could shift to a bridge site and then to another adjacent top site, indicating a degree of mobility for $\mathrm{O}_{2} *$ on $\operatorname{Pt}(111)$. More important is the hydrogen bonding ( $\mathrm{HB}$ ) interaction between each of the $\mathrm{O}$ in $\mathrm{O}_{2} *$ and $\mathrm{H}_{2} \mathrm{O}$ molecules, which could lower the reaction barrier.

With such a small barrier, the dissociation of $\mathrm{O}_{2}$ on $\mathrm{Pt}(111)$ in alkaline solution is as facile as that in acidic solution. ${ }^{38}$ Typically it produces one $\mathrm{O}^{*}$, stabilized at a fcc site, while the other $\mathrm{O}^{*}$ could pick up a $\mathrm{H}$ from a $\mathrm{H}_{2} \mathrm{O}^{*}$, producing two $\mathrm{OH}^{*}$ on $\mathrm{Pt}(111)$, as in a hydrolysis,

$$
\mathrm{O}^{*}+\mathrm{H}_{2} \mathrm{O}^{*} \rightarrow 2 \mathrm{OH}^{*}
$$

The dissociation barrier does not change significantly when charge is added or subtracted from the slab, although $\mathrm{O}^{*}$ is more likely to be stabilized on a bridge or even a top site when the slab is negatively charged. Several MTD runs are also conducted with $\mathrm{HOH} . . . \mathrm{O}-\mathrm{O}^{*}$ as the reaction coordinate, to explore the channel for the formation of $\mathrm{OOH}^{*}$. In all cases, the $\mathrm{O}^{-} \mathrm{O}^{*}$ is broken while $\mathrm{OH}^{*}$ is formed, which is again similar to the situation in acidic media ${ }^{37}$ and indicates $\mathrm{OOH}^{*}$ formation as a minor channel because $\mathrm{O}-\mathrm{O} *$ bond is easily broken.

\section{interpretation of cyclic voltammogram and polarization curve}

For the ORR on $\operatorname{Pt}(111)$ in acid media, we have demonstrated recently by an AIMD/MTD study that the branching ratio of the two competing channels for $\mathrm{O}^{*}$ hydrogenation, either by reaction with a $\mathrm{H}^{+}$(protonation) or by reaction with a $\mathrm{H}_{2} \mathrm{O}$ (hydrolysis), is very sensitive to the electrode potential $U{ }^{38}$ The protonation channel can be bypassed by the electrochemically inactive hydrolysis channel for $U$ higher than $0.8 \mathrm{~V}$, which is responsible for the irreversible feature in the oxide region $(0.8 \mathrm{~V}<U<1.2 \mathrm{~V})$ observed in its $\mathrm{CV}$. As shown in Figure 2, the oxide region of the $\mathrm{CV}$ for oxygen free $\mathrm{H}_{2} \mathrm{O}$ in $0.1 \mathrm{M} \mathrm{NaOH}$, plotted with $\mathrm{U}$ in $\mathrm{RHE}$, is broadly similar to that

measured in $0.1 \mathrm{M} \mathrm{HClO}_{4}{ }^{51}$. Hereby we demonstrate by reaction equations that there are intrinsic links between the two CVs, despite the very different $\mathrm{pH}$ values. 


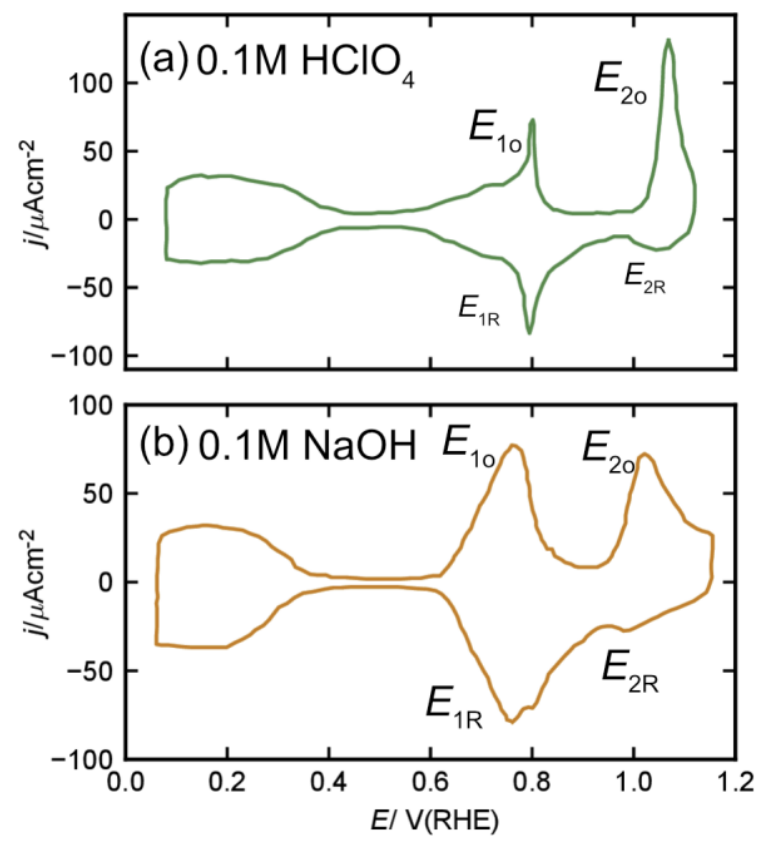

Figure 2: The oxygen-free cyclic voltammogram for $\mathrm{Pt}(111)$ in (a) $0.1 \mathrm{M} \mathrm{HClO} 4$, digitized from ref.51, (b) $0.1 \mathrm{M} \mathrm{NaOH}$, digitized from ref.45

In the acid $\mathrm{CV}$, peak $\mathrm{E}_{1 \mathrm{O}}$ is due to

$$
\mathrm{H}_{2} \mathrm{O}^{*} \rightarrow \mathrm{OH}^{*}+\mathrm{H}^{+}+\mathrm{e}^{-}
$$

while peak $\mathrm{E}_{1 \mathrm{R}}$ is due to its reverse process,

$$
\mathrm{OH}^{*}+\mathrm{H}^{+}+\mathrm{e}^{-} \rightarrow \mathrm{H}_{2} \mathrm{O}^{*}
$$

In alkaline media, $\mathrm{OH}^{-}$should be added to both sides of the reaction, neutralizing $\mathrm{H}^{+}$to $\mathrm{H}_{2} \mathrm{O}$ and transforming Reaction 2 to

$$
\mathrm{H}_{2} \mathrm{O}^{*}+\mathrm{OH}^{-} \rightarrow \mathrm{OH}^{*}+\mathrm{H}_{2} \mathrm{O}+\mathrm{e}^{-}
$$

Removing the adsorption of water from consideration, the process is essentially $\mathrm{OH}^{-}$adsorption

$$
\mathrm{OH}^{-} \rightarrow \mathrm{OH}^{*}+\mathrm{e}^{-}
$$

which is responsible for $\mathrm{E}_{1 \mathrm{O}}$ in the alkaline $\mathrm{CV}$. Similarly, its reverse, $\mathrm{OH}^{*}$ desorption,

$$
\mathrm{OH}^{*}+\mathrm{e}^{-} \rightarrow \mathrm{OH}^{-}
$$

is responsible for $\mathrm{E}_{1 \mathrm{R}}$ in Figure $2 \mathrm{~b}$.

Peak $\mathrm{E}_{2} \mathrm{O}$ in the acid $\mathrm{CV}$ is due to $\mathrm{OH}^{*}$ dissociation,

$$
\mathrm{OH}^{*} \rightarrow \mathrm{O}^{*}+\mathrm{H}^{+}+\mathrm{e}^{-} \text {. }
$$

However, its reverse, $\mathrm{O}^{*}$ protonation,

$$
\mathrm{O}^{*}+\mathrm{H}^{+}+\mathrm{e}^{-} \rightarrow \mathrm{OH}^{*},
$$


is bypassed by $\mathrm{O}^{*}$ hydrolysis (Reaction 1 ), which does not involve charge transfer with the electrode. This is the reason for the absence of a peak $\mathrm{E}_{2 \mathrm{R}}$ in the cathode scan. ${ }^{38} \mathrm{By}$ adding $\mathrm{OH}^{-}$to both sides of reaction (7), the corresponding equation in alkaline medium is

$$
\mathrm{OH}^{*}+\mathrm{OH}^{-} \rightarrow \mathrm{O}^{*}+\mathrm{H}_{2} \mathrm{O}+\mathrm{e}^{-}
$$

for peak $\mathrm{E}_{2 \mathrm{O}}$. The corresponding reduction reaction is obtained by writing it in reverse,

$$
\mathrm{O}^{*}+\mathrm{H}_{2} \mathrm{O}+\mathrm{e}^{-} \rightarrow \mathrm{OH}^{*}+\mathrm{OH}^{-} .
$$

However, this reaction should also be bypassed by $\mathrm{O}^{*}$ hydrolysis (Reaction 1 ) for $U>\mathrm{E}_{10}$. In such a high $U$ region, the equilibrium between reactions 5 and 6 favors $\mathrm{OH}^{-}$adsorption. Even when Reaction 10 takes place, it would be followed by $\mathrm{OH}^{-}$adsorption. As a result, the overall process should be $\mathrm{O}^{*}$ hydrolysis and the net reduction current is zero. Again, $\mathrm{O}^{*}$ hydrolysis is responsible for the irreversible oxide region in the alkaline CV. In acid solution, the dominance of $\mathrm{O}^{*}$ hydrolysis over $\mathrm{O}^{*}$ protonation is linked to the equilibrium of $\mathrm{OH}^{*}$ protonation and $\mathrm{H}_{2} \mathrm{O}^{*}$ dissociation (reactions 2 and 3), and the dramatic change in branching ratio is identified by MTD simulations. ${ }^{38}$ In alkaline solution, the dominance of $\mathrm{O}^{*}$ hydrolysis for $U>\mathrm{E}_{10}$ is a matter of simple logic, the natural consequence of the relative stability of $\mathrm{OH}^{*}$ over $\mathrm{OH}^{-}$.

As in the case of ORR in acid media, ${ }^{38}$ the dominance of the $\mathrm{O}^{*}$ hydrolysis for $U>\mathrm{E}_{10}$ is also crucial for understanding the origin of the onset overpotential and the shape of the polarization curve. Firstly, with $\mathrm{O}^{*}$ hydrogenation going through the electrochemically inactive hydrolysis channel, the ORR current is stopped at the potential for the equilibrium between $\mathrm{OH}^{*}$ desorption and $\mathrm{OH}^{-}$adsorption, $E_{O H^{-}}^{0} / O H^{*}=1.03 \mathrm{~V}(\mathrm{RHE})^{52}$. The overall $\mathrm{ORR}$ equilibrium potential $E_{O R R}^{0}=$ $1.23 \mathrm{~V}$ is actually unreachable, and the origin for the well-known large onset overpotential for ORR is due to the gap between $E_{O H^{-}}^{0} / O H^{*}$ and $E_{O R R}^{0}$. Secondly, to model the polarization curve, the overpotential should be calculated with $E_{O H^{-}}^{0} / O H^{*}$, rather than $E_{O R R}^{0}$, as the reference potential. Finally, for $U$ close to $1.0 \mathrm{~V}$, the correctly calculated overpotential is approaching zero and the polarization curve should be fitted to the Butler-Volmer Equation, rather than to the Tafel Equation which is valid only for overpotential $>0.1 \mathrm{~V}$. In previous studies, ${ }^{40-42}$ the overpotential has been calculated with $E_{O R R}^{0}$ as the reference and fitted to the Tafel Equation, producing a Tafel slope $60 \mathrm{mV} /$ decade for the polarization curve, but there are indications of non-linearity in the fitted Tafel line (see, for example, Figure 3 in Ref. [41]). In these aspects, ORR on Pt(111) in alkaline media is again similar to that in acid media. ${ }^{38}$ 
conditions for observing $\mathrm{OH}^{-}$in double layer

However, in our AIMD simulations, there is one aspect of the ORR reaction that is very different between the acid and alkaline media. With a $\mathrm{HBr}|\operatorname{Pt}(111)| n \mathrm{H}_{2} \mathrm{O}$ model for the acid media, the back and forth between $\mathrm{H}_{2} \mathrm{O}^{*}$ dissociation and $\mathrm{OH}^{*}$ protonation are frequently observed as spontaneous events during AIMD simulations at $300 \mathrm{~K} \cdot{ }^{37,38}$ It is in line with the expectation that $\mathrm{OH}^{*}$ protonation is active in the region $0.6 \mathrm{~V}<U<1.0 \mathrm{~V}$. In contrast, with a $\mathrm{NaOH}|\mathrm{Pt}(111)| n \mathrm{H}_{2} \mathrm{O}$ model for the alkaline media, $\mathrm{OH}^{-}$is spontaneously adsorbed on $\mathrm{Pt}(111)$ and stuck there without desorption during AIMD simulations, despite the fact that the CV in alkaline medium (Figure 2a) also indicates a broad electrode potential range for $\mathrm{OH}^{*}$ desorption being active. It indicates that our model favors $\mathrm{OH}^{*}$ over solvated $\mathrm{OH}^{-}$, and we have tried three ways to improve it.

The first way is to increase the surface coverage of $\mathrm{OH}^{*}$. Following the dissociation of $\mathrm{O}_{2} *$, $\mathrm{OH}^{*}$ is produced by the hydrogenation of $\mathrm{O}^{*}$, as discussed above. It is well-known that the $\mathrm{OH}^{*}$ coverage is high ${ }^{42}$ especially when $U$ is close to $0.9 \mathrm{~V}$. Additional $\mathrm{OH}^{*}$ groups are added on the surface, so that the models become $\mathrm{NaOH}\left|m \mathrm{OH}^{*}\right| \mathrm{Pt}(111) \mid n \mathrm{H}_{2} \mathrm{O}$, with $m=6$ and 8 , corresponding to total $\mathrm{OH}^{*}$ coverage of $3 / 8$ and $1 / 2$, respectively, since there are 16 surface sites in our $(4 \times 4)$ slab model. However, in all these cases, the $\mathrm{OH}^{-}$ends up as $\mathrm{OH}^{*}$ on $\mathrm{Pt}(111)$.

The second way is to vary the electrode potential $U . \mathrm{OH}^{*}$ desorption should be easier when $U$ goes more negative, which can be modeled by adding a constant negative charge to the slab. The amount of charge is $0.5 \mathrm{e}^{-}, 1.0 \mathrm{e}^{-}, 1.5 \mathrm{e}^{-}$, and $2.0 \mathrm{e}^{-}$, respectively, and two separate models, $\mathrm{NaOH}|\mathrm{Pt}(111)| n \mathrm{H}_{2} \mathrm{O}$ and $\mathrm{NaOH}\left|6 \mathrm{OH}^{*}\right| \operatorname{Pt}(111) \mid n \mathrm{H}_{2} \mathrm{O}$, are employed to add some variations to the $\mathrm{OH}^{*}$ coverage. For both models, solvated $\mathrm{OH}^{-}$is stabilized during AIMD simulations only at $1.5 \mathrm{e}^{-}$, and $2.0 \mathrm{e}^{-}$, which corresponds roughly to shifting $U$ by $-1.5 \mathrm{~V}$ and $-2.0 \mathrm{~V}$ in our models as calculated by the double reference method (see Figure S2 in Supplementary Materials). ${ }^{53,54}$ Unfortunately, such a negative $U$ is definitely outside the range of the operating electrode potential of ORR.

The third way is to add a second $\mathrm{NaOH}$. The distribution of solvated ions in the electric double layer near an electrode surface is dependent on surface charging, adsorbed species, and the electrostatic interactions between the charged interface and solvated ions. ${ }^{55,56}$ Recent measurements by electrochemical impedance spectroscopy indicate that the effective cation concentration of alkali metal cations in the electric double layer on a model $\mathrm{Pt}(111)$ electrode could be $\sim 80$ times of the bulk concentration, valued around $4 \mathrm{M}^{57} \mathrm{~A}$ second $\mathrm{NaOH}$ in our model 
increases the $\mathrm{Na}^{+}$concentration in the double layer, to a mole ratio of $\sim 1: 20$ between $\mathrm{Na}^{+}$and $\mathrm{H}_{2} \mathrm{O}$. When the volume change due to the dissolution of $\mathrm{NaOH}$ in $1 \mathrm{~L}$ water is neglected, the mole ratio between $\mathrm{Na}^{+}$and $\mathrm{H}_{2} \mathrm{O}$ in a $1 \mathrm{M} \mathrm{NaOH}$ solution is $\sim 1: 56$. The 1:20 ratio in our model roughly corresponds to a concentration close to $3 \mathrm{M}$ for $\mathrm{Na}^{+}$in the solvation layer. Again two models, $2 \mathrm{NaOH}|\mathrm{Pt}(111)| n \mathrm{H}_{2} \mathrm{O}$ and $2 \mathrm{NaOH} 6 \mathrm{OH}^{*}|\mathrm{Pt}(111)| n \mathrm{H}_{2} \mathrm{O}$, are tested, and in both models, the second $\mathrm{OH}^{-}$can exist as a solvated ion in the double layer, while the first $\mathrm{OH}^{-}$stays on $\mathrm{Pt}(111)$ as $\mathrm{OH}^{*}$. In other words, it's the increased cation concentration that can stabilize solvated $\mathrm{OH}^{-}$, which could not be achieved by either higher $\mathrm{OH}^{*}$ coverage or adding up to $1 \mathrm{e}^{-}$to the $\operatorname{Pt}(111)$ slab.

mechanism for $\mathrm{OH}^{*}$ desorption

To obtain the free energy barrier for $\mathrm{OH}^{*}$ desorption on $\mathrm{Pt}(111)$, we first use a $\mathrm{Pt}-\mathrm{OH}^{*}$ distance as the reaction coordinate for MTD simulations, since it seems obvious that $\mathrm{OH}^{*}$ desorption should involve the breaking of such a bond. However, for the dozen MTD runs over $\mathrm{Pt}-\mathrm{OH}^{*}$, using either $2 \mathrm{NaOH}|\mathrm{Pt}(111)| n \mathrm{H}_{2} \mathrm{O}$ or $2 \mathrm{NaOH}\left|6 \mathrm{OH}^{*}\right| \mathrm{Pt}(111) \mid n \mathrm{H}_{2} \mathrm{O}$ model, the stretched $\mathrm{OH}^{*}$ picks a $\mathrm{H}$ from either a water molecule or an adsorbed $\mathrm{OH}^{*}$ so that when $\mathrm{Pt}-\mathrm{O}$ is broken, it's actually between a $\mathrm{Pt}$ and a $\mathrm{H}_{2} \mathrm{O}$ molecule. Only two MTD runs lead almost to the breaking of $\mathrm{Pt}-\mathrm{OH}^{*}$ bond, but the $\mathrm{OH}$ does not desorb into the solvation layer. Instead, it stays close to the surface and adsorbs on another Pt site, with the overall process being $\mathrm{OH}^{*}$ migration, rather than $\mathrm{OH}^{*}$ desorption. (See Tables S2 and S3, and Figure S3).
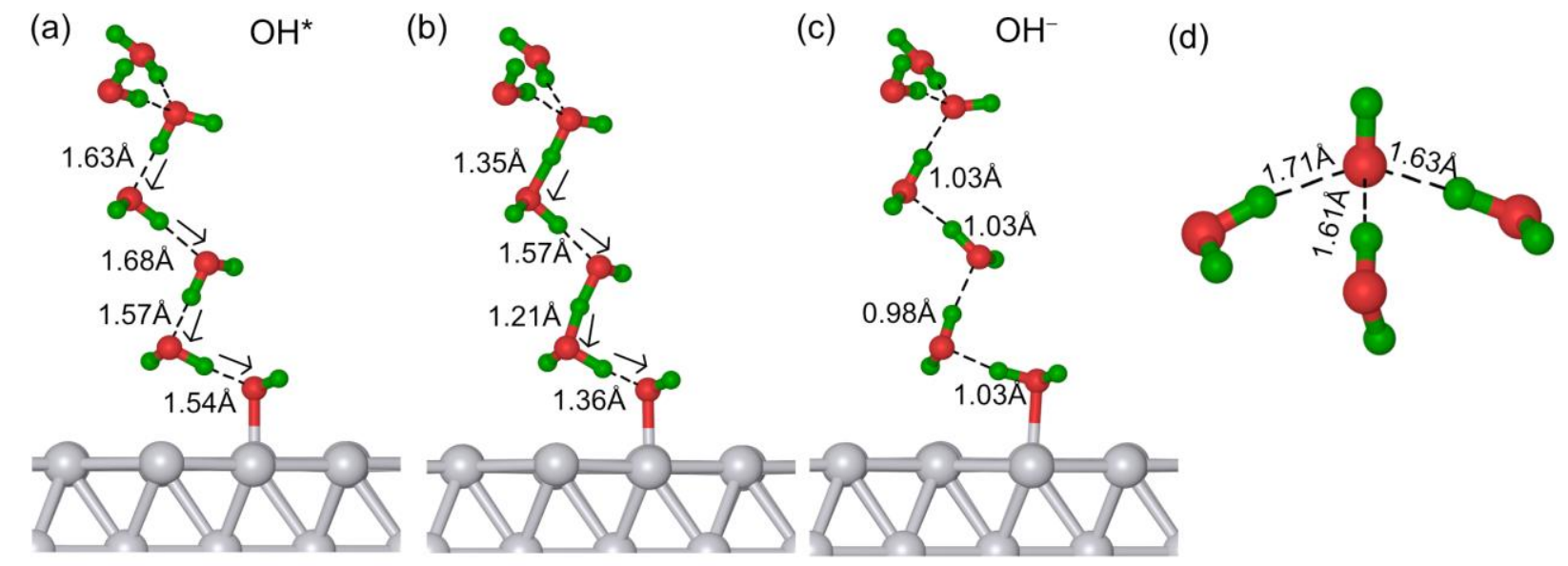

Figure 3: $\mathrm{OH}^{*}$ desorption achieved by a proton transfer process, producing an $\mathrm{OH}^{-}$right in the solution layer while transforming $\mathrm{OH}^{*}$ into $\mathrm{H}_{2} \mathrm{O}^{*}$, through (a), (b) and (c) (background solvent $\mathrm{H}_{2} \mathrm{O}$ molecules not shown). (d) optimized $\mathrm{OH}^{-}\left(\mathrm{H}_{2} \mathrm{O}\right)_{3}$ structure. 
When the stretched $\mathrm{OH}^{*}$ picks up a $\mathrm{H}$ from a solvent $\mathrm{H}_{2} \mathrm{O}$, an $\mathrm{OH}^{-}$is produced in the solution layer as well. As shown in Figure 3 for such a step, the $\mathrm{H}^{+}$produced by the ionic dissociation of a $\mathrm{H}_{2} \mathrm{O}$ is transferred through the inter-water $\mathrm{HB}$ network to an $\mathrm{OH}^{*}$, producing $\mathrm{H}_{2} \mathrm{O}^{*}$ on $\mathrm{Pt}(111)$ and leaving an $\mathrm{OH}^{-}(\mathrm{aq})$. Instead of breaking a $\mathrm{Pt}-\mathrm{OH}^{*}$ bond as implied in Reaction $6, \mathrm{OH}^{*}$ desorption can be achieved by proton transfer,

$$
\mathrm{OH}^{*} \ldots\left(\mathrm{H}_{2} \mathrm{O}\right)_{n} \ldots \mathrm{H}_{2} \mathrm{O}+e^{-} \rightarrow{ }^{*} \mathrm{OH}_{2} \ldots\left(\mathrm{H}_{2} \mathrm{O}\right)_{n} \ldots O H^{-} .
$$

The underlying physical reason favoring such a mechanism is the strong solvation of $\mathrm{OH}^{-}$by $\mathrm{H}_{2} \mathrm{O}$, which has been explored extensively in the gas phase by studying hydrated hydroxide clusters, $\mathrm{OH}^{-}\left(\mathrm{H}_{2} \mathrm{O}\right)_{n}{ }^{49,58,59}$ In terms of the stepwise hydration energy, defined as

$$
E_{n}=E\left[\mathrm{OH}^{-}\left(\mathrm{H}_{2} \mathrm{O}\right)_{n}\right]-E\left[\mathrm{OH}^{-}\left(\mathrm{H}_{2} \mathrm{O}\right)_{n-1}\right]-E\left[\mathrm{H}_{2} \mathrm{O}\right],
$$

the estimated value is $-27.0,-20.1$, and $-16.9 \mathrm{kcal} / \mathrm{mol}$ for $n=1,2$, and 3 , which are much larger in magnitude than the energy of a typical $\mathrm{HB}$ around $5 \mathrm{kcal} / \mathrm{mol} .{ }^{59}$

These strong hydrogen bonds around $\mathrm{OH}^{-}$, as shown in Figure 3d, are always on its oxygen end where the negative charge is localized, while its hydrogen end is usually unsolvated in $\mathrm{OH}^{-}\left(\mathrm{H}_{2} \mathrm{O}\right)_{n}$ and would only form a hydrogen bond of typical strength. ${ }^{49}$ When a $\mathrm{Pt}-\mathrm{OH}^{*}$ distance is stretched to produce an $\mathrm{OH}^{-}$, the space to the oxygen side of the nascent $\mathrm{OH}^{-}$is, however, occupied by the $\mathrm{Pt}(111)$ slab, making it difficult for water molecules to solvate the $\mathrm{OH}^{-}$from the direction most favorable for hydrogen bonding and incurring an energy penalty. In contrast, when an $\mathrm{OH}^{-}$is produced directly in the solution layer, with a proton transferred to an $\mathrm{OH}^{*}$, the $\mathrm{HB}$ network is readily adjusted for the solvation of $\mathrm{OH}^{-}$, as long as there is at least one water layer separating it from the surface.

Similarly, direct adsorption by the collision of an $\mathrm{OH}^{-}$with $\mathrm{Pt}(111)$ is also unfavorable. For the formation of $\mathrm{Pt}-\mathrm{OH}^{*}$ bond, it would require the stripping away of the $\mathrm{H}_{2} \mathrm{O}$ molecules solvating the oxygen end of $\mathrm{OH}^{-}$, and the energy cost would be high, based on the values of the stepwise solvation energy for $\mathrm{OH}^{-}$cited above. It's more facile to go through the path from Figure 3c, to $3 b$, to $3 a$,

$$
{ }^{*} \mathrm{OH}_{2} \ldots\left(\mathrm{H}_{2} \mathrm{O}\right)_{n} \ldots \mathrm{OH}^{-} \rightarrow \mathrm{OH}^{*} \ldots\left(\mathrm{H}_{2} \mathrm{O}\right)_{n} \ldots \mathrm{H}_{2} \mathrm{O}+e^{-},
$$

as verified upon close examinations on our AIMD trajectories.

cross sphere electrode reaction 
Such desorption/adsorption processes represent a new type of electrochemical reactions, involving both inner sphere (the electrode surface) and outer sphere (the solvation layer). For $\mathrm{OH}^{*}$ desorption, the reactant $\mathrm{OH}^{*}$ is on the surface while the product $\mathrm{OH}^{-}$is in the solvation layer. For $\mathrm{OH}^{-}$adsorption, it is reversed. Such a cross-sphere reaction is dependent on both the electrode material through surface interactions $\left(\mathrm{OH}^{*}\right)$ and the electric double layer through the solvation of $\mathrm{OH}^{-}$. Although an electron appears in the formal equation (Reactions 11 and 13), the carrier for the charge transfer is actually a proton, and the reaction proceeds on the ground state surface through the solvation layer, without electron tunneling.

The underlying reason for a cross sphere electrode reaction is the strong solvation around $\mathrm{OH}^{-}$, which cannot be satisfied for an $\mathrm{OH}^{-}$close to the electrode and interacting directly with the surface with its negatively charged $\mathrm{O}$ end. Herein is a contrast between $\mathrm{H}^{+}$and $\mathrm{OH}^{-}$, both of which have strong solvation interactions with $\mathrm{H}_{2} \mathrm{O}$ and play important roles in many electrochemical reactions. $\mathrm{H}^{+}$is highly mobile in a $\mathrm{HB}$ network and can directly attack adsorbed species, such as $\mathrm{OH}^{*}$ and $\mathrm{O}^{*} .{ }^{37,38}$ In contrast, $\mathrm{OH}^{-}$is produced or neutralized in the solution layer, which is facilitated by proton transfer, albeit in alkaline media.

To simulate such processes in MTD simulations, a better choice for the reaction coordinate than a $\mathrm{Pt}-\mathrm{OH}^{*}$ distance is the difference between two $\mathrm{OH}$ distances as defined in Figure $4 \mathrm{a} .{ }^{60,61} \mathrm{It}$ targets a specific $\mathrm{OH}^{*}$ on $\mathrm{Pt}(111)$ and facilitates a proton transfer to it. Typically, when the targeted $\mathrm{OH}^{*}$ picks up a $\mathrm{H}^{+}$from the solution layer to form $\mathrm{H}_{2} \mathrm{O}^{*}$, a solvated $\mathrm{OH}^{-}$is produced at the same time. When this $\mathrm{H}_{2} \mathrm{O} *$ loses a $\mathrm{H}^{+}$, the $\mathrm{OH}^{-}(\mathrm{aq})$ is neutralized and an $\mathrm{OH}^{*}$ is produced, in an overall process of $\mathrm{OH}^{-}$adsorption. 
(a)

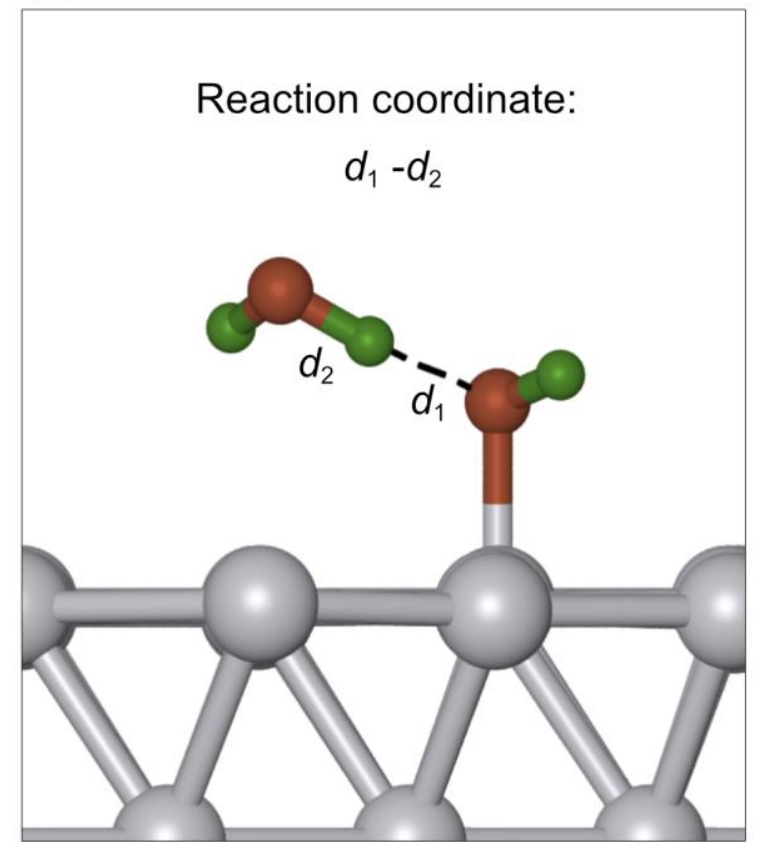

(b)
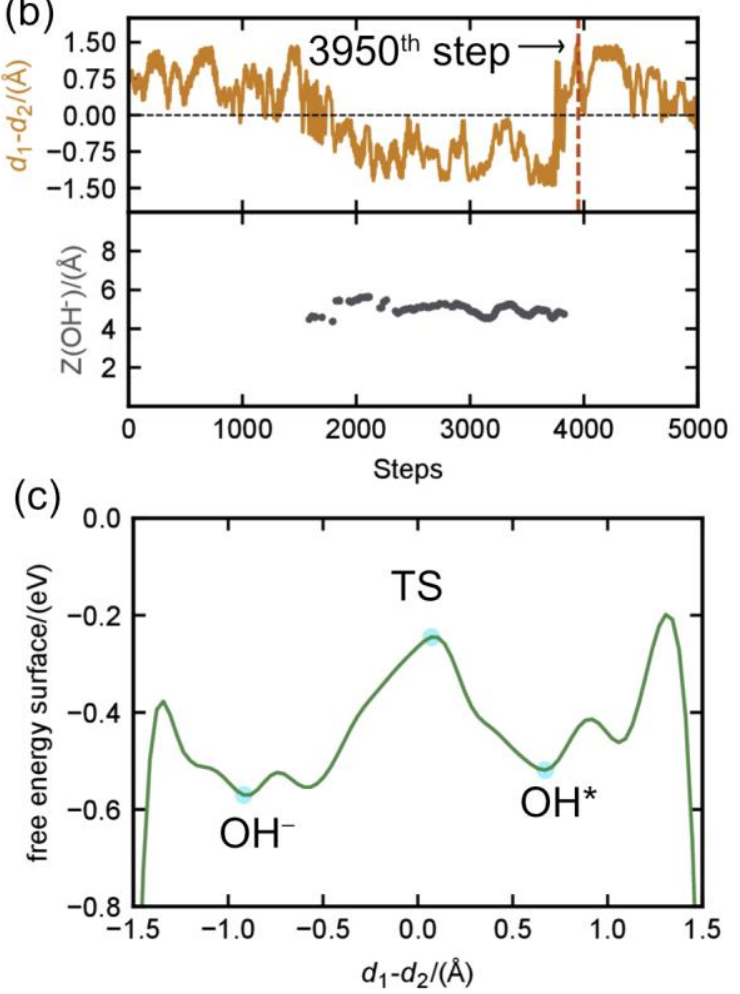

Figure 4: A typical MTD simulation with $d_{1}-d_{2}$ as the reaction coordinate for $\mathrm{OH}^{*}$ desorption. (a) The illustration of the two $\mathrm{OH}$ distance $d_{1}$ and $d_{2}$. When $d_{1}$ is shorter than $d_{2}$, a hydrogen has been captured by the targeted $\mathrm{OH}^{*}$ which becomes a $\mathrm{H}_{2} \mathrm{O}^{*}$, usually producing an $\mathrm{OH}^{-}(\mathrm{aq})$ at the same time. (b). The time evolution of $d_{1}-d_{2}$ during a typical MTD run and the distance of $\mathrm{OH}^{-}(\mathrm{aq})$ to the surface, defined as the difference between the $\mathrm{z}$ coordinates of $\mathrm{O}$ in $\mathrm{OH}^{-}(\mathrm{aq})$ and of the surface $\mathrm{Pt}$ atoms. Notice the time evolution of this distance could be jumpy, due to the proton transfer between $\mathrm{OH}^{-}(\mathrm{aq})$ with surrounding $\mathrm{H}_{2} \mathrm{O}$ molecules. It could even capture a proton from an adsorbed $\mathrm{H}_{2} \mathrm{O} *$ to produce $\mathrm{OH}^{*}$ so that $\mathrm{OH}^{-}$would disappear from the solution. (c) The free energy plot against $d_{1}-d_{2}$ obtained from the MTD run shown in (b) with a cut off at 3950 steps. (For more details about these MTD runs, please see the supplementary materials.)

The barriers calculated for $\mathrm{OH}^{*}$ desorption are presented in Table 1, employing two models, $2 \mathrm{NaOH}|\mathrm{Pt}(111)| n \mathrm{H}_{2} \mathrm{O}$ and $2 \mathrm{NaOH}\left|6 \mathrm{OH}^{*}\right| \mathrm{Pt}(111) \mid n \mathrm{H}_{2} \mathrm{O}$, respectively. The value is in the range of 0.2 0.3 eV, and increases with both the $\mathrm{OH}^{*}$ surface coverage and the positive charge in the slab, although the increase is typically within the error of sampling. 


\begin{tabular}{cccc}
\hline Model & $\Delta \mathrm{q}(|e|)$ & Barrier(eV) & $\begin{array}{c}\text { Number of } \\
\text { trajectories }\end{array}$ \\
\hline $2 \mathrm{NaOH}|\operatorname{Pt}(111)| n \mathrm{H} 2 \mathrm{O}$ & 0.00 & $0.23 \pm 0.06$ & 4 \\
$2 \mathrm{NaOH}|6 \mathrm{OH} *| \operatorname{Pt}(111) \mid n \mathrm{H} 2 \mathrm{O}$ & 0.00 & $0.26 \pm 0.03$ & 5 \\
& -0.25 & $0.26 \pm 0.05$ & 4 \\
& 0.25 & $0.32 \pm 0.05$ & 4 \\
$2 \mathrm{LiOH}|6 \mathrm{OH} *| \mathrm{Pt}(111) \mid n \mathrm{H} 2 \mathrm{O}$ & 0.00 & $0.39 \pm 0.09$ & 4 \\
\hline
\end{tabular}

Table 1: $\mathrm{OH}^{*}$ desorption barrier calculated by MTD simulations with $d_{1}-d_{2}$ as the reaction coordinate. (For more details about these MTD runs, please see the supplementary materials.)

cation effect for alkaline ORR on Pt(111)

When $\mathrm{NaOH}$ is replaced by $\mathrm{LiOH}$, as in the $2 \mathrm{LiOH}\left|6 \mathrm{OH}^{*}\right| \mathrm{Pt}(111) \mid n \mathrm{H}_{2} \mathrm{O}$ model, the average barrier for $\mathrm{OH}^{*}$ desorption reaches $0.39 \mathrm{eV}$, the highest average value in Table 1. It is in agreement with the experimentally observed cation effect: the ORR activity on $\mathrm{Pt}(111)$ is reduced in alkaline medium, when the cation in the solvation layer is changed from $\mathrm{Na}^{+}$to $\mathrm{Li}^{+}$. While the stabilizing effect of the cation on $\mathrm{OH}^{*}$ could be part of the reasons for such observations, ${ }^{12,19}$ there is another side to $\mathrm{OH}^{*}$ desorption as $\mathrm{OH}^{-}(\mathrm{aq})$ is produced directly in the solvation layer. As an anion, the interaction of $\mathrm{OH}^{-}$with cations should be stronger than that between $\mathrm{OH}^{*}$ and cations. It also has strong interactions with solvent $\mathrm{H}_{2} \mathrm{O}$ molecules and its presence should have significant effects on the solvation layer close to the electrode surface as well. These considerations lend support to the suggestion ${ }^{20}$ that the stabilization of negatively charge intermediates, in this case, $\mathrm{OH}^{-}$, could significantly contribute to the cation effects.

While it's gratifying to reproduce such effects for ORR, we would also like to notice the complexity of this problem. The concentration of cations in the double layer near $\operatorname{Pt}(111)$ in alkaline medium is not known yet, although it could vary significantly with the electrode potential and the cation identity. ${ }^{57}$ The $\mathrm{OH}^{*}$ coverage on $\operatorname{Pt}(111)$ could also vary significantly with $U{ }^{62}$ It is somewhat counter-intuitive that while $\mathrm{Na}^{+}$is less polarizing than $\mathrm{Li}^{+}$, solvated $\mathrm{Na}^{+}$actually stabilize solvated $\mathrm{OH}^{-}$more than solvated $\mathrm{Li}^{+}$. But cation-anion interaction is only one of the components among the electrostatic interactions in an interfacial solvation layer, involving not 
only solute-solute, but also solute-solvent and solvent-solvent interactions, all in the presence of a charged surface. Sorting out these factors would require more elaborate models and longer simulations.

What our results do establish is that $\mathrm{OH}^{*}$ desorption produces $\mathrm{OH}^{-}$in the solvation layer right away, and the reaction is sensitive to both cation identity and concentration. As $U$ increases, cations are pushed away from the electrode surface, as demonstrated by x-ray scattering experiments, ${ }^{13,14}$ which makes $\mathrm{OH}^{-}$less stable in the double layer and tilts the desorption/adsorption equilibrium towards $\mathrm{OH}^{*}$. How the cation concentration changes with the distance to the surface and its variation with $U$ should be the key factors determining the equilibrium of $\mathrm{OH}^{*} / \mathrm{OH}^{-}$equilibrium.

It also points to the possibility of modifying the outer sphere for the enhancement of ORR activity. For example, with Zwitterion ions of the type $\mathrm{O}^{-}-$chain $-\mathrm{R}^{+}$, it should be possible to partially cover the electrode with their $\mathrm{O}^{-}$ends attached to the surface, resulting in a layer of positive charge $\mathrm{R}^{+}$in the outer sphere. Unlike the solvated metal cations, $\mathrm{R}^{+}$ends are fastened to the electrode surface by chains, which makes the concentration of $\mathrm{R}^{+}$less sensitive to the change of $U$. It would be interesting to explore whether such a layer of $\mathrm{R}^{+}$would make the $\mathrm{OH}^{*}$ desorption more favorable in future studies.

\section{summary}

By AIMD/MTD simulations, we have explored the reaction channels of ORR on $\operatorname{Pt}(111)$ in alkaline media. The dissociation of $\mathrm{O}_{2}^{*}$ is facile, producing $\mathrm{OH}^{*}$ and $\mathrm{O}^{*}$. $\mathrm{OH}^{*}$ desorption is identified as the key reduction step in the overall mechanism, because above the $\mathrm{OH}^{*} / \mathrm{OH}^{-}$ equilibrium potential, the hydrogenation of $\mathrm{O}^{*}$ is dominated by the electrochemically inactive $\mathrm{O}^{*}$ hydrolysis channel. Similar to ORR in acidic medium, the thermodynamic ORR equilibrium potential is unreachable. The ORR in alkaline media is switched off at $\mathrm{OH}^{*} / \mathrm{OH}$ equilibrium potential, and the polarization curve near this equilibrium should be modeled by the Butler-Volmer Equation, rather than the Tafel Equation.

More importantly, $\mathrm{OH}^{*}$ desorption is identified as a cross sphere electrode reaction, with the reactant $\mathrm{OH}^{*}$ in the inner sphere and the product $\mathrm{OH}^{-}$in the solvation layer. The carrier for the charge transfer is a proton, rather than an electron, with the reaction proceeding on the ground state surface. The reaction rate is dependent on both the electrode material (through $\mathrm{OH}^{*}$ ) and the 
solvation environment in the double layer (through $\mathrm{OH}^{-}$), which accounts for the experimental observations of cation effects.

The presence of such a cross sphere reaction is due to the strong solvation of $\mathrm{OH}^{-}$, as the direct breaking or formation of $\mathrm{Pt}-\mathrm{OH}^{*}$ bond would disrupt the strong hydrogen bonds on the $\mathrm{O}$ end of $\mathrm{OH}^{-}$and is energetically very unfavorable. It should play a significant role for electrochemical processes in alkaline media, whenever $\mathrm{OH}^{*}$ desorption/ $\mathrm{OH}^{-}$adsorption are involved. More generally, when the adsorption/desorption of a strongly solvated electrolyte is involved, the possibility of a cross sphere mechanism should also be considered, which opens up the possibility of modifying the cation distribution in the outer sphere for enhancing the electrocatalytic rate.

\section{Computational methodology}

All molecular dynamics calculations are performed with the Vienna ab initio package (VASP). ${ }^{63,64}$ The total energy and forces are calculated within the framework of DFT, using the PBE exchange-correlation functional, ${ }^{65}$ with the dispersion interaction corrected by the D3 scheme. ${ }^{66}$ The cutoff energy for the plane waves is $400 \mathrm{eV}$, and the atomic core region is described by PAW pseudopotentials. ${ }^{67}$ The gamma point is used to integrate the Brillouin zone, and dipole correction along the Z-direction is also added. ${ }^{68}$

$\operatorname{Pt}(111)$ is modeled by a $(4 \times 4)$ surface slab of 3 layers, with the bottom two layers fixed in positions. The lengths of $a$ and $b$ are both $11.245 \AA$, optimized from the unit cell of Pt metal, while the length of $c$ is elongated to $39.6 \AA$, leaving enough space for an interfacial liquid layer of water molecules and a $20 \AA$ vacuum region. There are originally 42 water molecules, arranged in standard ice structure on the slab and relaxed by thermal annealing for 10,000 time steps. It is further optimized to reduce the forces on atoms to $0.02 \mathrm{eV} / \AA$.

An $\mathrm{OH}^{*}$ is introduced into the model by adding one $\mathrm{NaOH}$ into the liquid water layer, the dissociation of which produces a solvated $\mathrm{Na}^{+}$and an $\mathrm{OH}^{*}$ adsorbed on the slab. The structure is relaxed by another round of annealing and optimization, as reported in our previous study. ${ }^{38}$ Adsorbed $\mathrm{O}_{2} *$ is introduced by a similar procedure of relaxation and optimization. In molecular dynamics simulations, hydrogen mass is set to 2 amu and the time step is $1.2 \mathrm{fs}$.

In the metadynamics simulations, ${ }^{69,70}$ a bias potential $V_{\text {bias }}$ is added to the Hamiltonian, so that 


$$
\widetilde{H}=H+V_{\text {bias }} \text {. }
$$

$V_{\text {bias }}$ is time dependent and defined as a summation of Gaussian hills,

$$
V_{\text {bias }}=h \sum_{i=1}^{\left[t / t_{G}\right]} \exp \left\{-\frac{\left|\xi^{(t)}-\xi^{\left(i \cdot t_{G}\right)}\right|^{2}}{2 \omega^{2}}\right\}
$$

with $h$ being the Gaussian height, $w$ the Gaussian width, $t_{G}$ the frequency to add the Gaussian function, and $\xi$ the collective variable (i.e., the reaction coordinate). The parameters are $h=0.03$, $w=0.1$ and $t_{G}=25$, obtained after trial runs. The simulation temperature is set to $300 \mathrm{~K}$.

The $\mathrm{OH}^{-}\left(\mathrm{H}_{2} \mathrm{O}\right)_{3}$ is optimized with B3LYP ${ }^{71,72}$ method and 6-311++G $(\mathrm{d}, \mathrm{p})$ basis set $^{73}$ using the Gaussian 09 programs $^{74}$, with Grimme’s DFT-D3 dispersion correction. ${ }^{75}$

\section{Acknowledgement}

This study is supported by a GRF Grant (14303114) from the Research Grants Council of Hong Kong SAR Government. We are grateful for the generous allocation of computer time on the HPC clusters at the Center for Scientific Modeling and Computation. Part of the simulations were performed at the Shanghai Supercomputer Center. 


\section{Reference}

(1) Bard, A. J.; Faulkner, L. R.: Electrochemical methods : fundamentals and applications; Second edition. ed.; Wiley: New York ; Chichester, 2001. pp. 116-117.

(2) Bard, A. J. Inner-Sphere Heterogeneous Electrode Reactions. Electrocatalysis and Photocatalysis: The Challenge. J. Am. Chem. Soc. 2010, 132, 7559-7567.

(3) Marković, N. M.; Ross Jr, P. N. Surface science studies of model fuel cell electrocatalysts. Surf. Sci. Rep. 2002, 45, 117-229.

(4) Hung, N. C.; Nagy, Z. KINETICS OF THE FERROUS FERRIC ELECTRODE-REACTION IN THE ABSENCE OF CHLORIDE CATALYSIS. J. Electrochem. Soc. 1987, 134, 2215-2220.

(5) Wandlowski, T.; Delevie, R. DOUBLE-LAYER DYNAMICS IN THE ADSORPTION OF TETRABUTYLAMMONIUM IONS AT THE MERCURY WATER INTERFACE .4. THE REDUCTION OF HEXAMMINE-COBALT(III) THROUGH TETRABUTYLAMMONIUM FILMS. J. Electroanal. Chem. 1995, 380, 201-207.

(6) Ramaswamy, N.; Mukerjee, S. Influence of Inner- and Outer-Sphere Electron Transfer Mechanisms during Electrocatalysis of Oxygen Reduction in Alkaline Media. J. Phys. Chem. C 2011, 115, 18015-18026.

(7) Kulkarni, A.; Siahrostami, S.; Patel, A.; Norskov, J. K. Understanding Catalytic Activity Trends in the Oxygen Reduction Reaction. Chem. Rev. 2018, 118, 2302-2312.

(8) Chen, W.; Huang, J.; Wei, J.; Zhou, D.; Cai, J.; He, Z.-D.; Chen, Y.-X. Origins of high onset overpotential of oxygen reduction reaction at Pt-based electrocatalysts: A mini review. Electrochem. Commun. 2018, 96, 71-76.

(9) Shao, M. H.; Chang, Q. W.; Dodelet, J. P.; Chenitz, R. Recent Advances in Electrocatalysts for Oxygen Reduction Reaction. Chem. Rev. 2016, 116, 3594-3657.

(10) Gottesfeld, S.; Dekel, D. R.; Page, M.; Bae, C.; Yan, Y. S.; Zelenay, P.; Kim, Y. S. Anion exchange membrane fuel cells: Current status and remaining challenges. J. Power Sources 2018, 375, 170-184.

(11) Ramaswamy, N.; Mukerjee, S. Alkaline Anion-Exchange Membrane Fuel Cells: Challenges in Electrocatalysis and Interfacial Charge Transfer. Chem. Rev. 2019, 119, 11945-11979.

(12) Strmcnik, D.; Kodama, K.; van der Vliet, D.; Greeley, J.; Stamenkovic, V. R.; Markovic, N. $M$. The role of non-covalent interactions in electrocatalytic fuel-cell reactions on platinum. Nat Chem 2009, 1, 466-472.

(13) Strmcnik, D.; van der Vliet, D. F.; Chang, K. C.; Komanicky, V.; Kodama, K.; You, H.; Stamenkovic, V. R.; Markovic, N. M. Effects of Li+, K+, and Ba2+ Cations on the ORR at Model and High Surface Area Pt and Au Surfaces in Alkaline Solutions. J. Phys. Chem. Lett. 2011, 2, 2733-2736.

(14) Nakamura, M.; Nakajima, Y.; Hoshi, N.; Tajiri, H.; Sakata, O. Effect of Non-Specifically Adsorbed lons on the Surface Oxidation of Pt(111). Chemphyschem 2013, 14, 2426-2431.

(15) Stoffelsma, C.; Rodriguez, P.; Garcia, G.; Garcia-Araez, N.; Strmcnik, D.; Markovic, N. M.; Koper, M. T. M. Promotion of the Oxidation of Carbon Monoxide at Stepped Platinum Single-Crystal Electrodes in Alkaline Media by Lithium and Beryllium Cations. J. Am. Chem. Soc. 2010, 132, 1612716133.

(16) Chen, X.; McCrum, I. T.; Schwarz, K. A.; Janik, M. J.; Koper, M. T. M. Co-adsorption of Cations as the Cause of the Apparent $\mathrm{pH}$ Dependence of Hydrogen Adsorption on a Stepped Platinum Single-Crystal Electrode. Angew. Chem. Int. Ed. 2017, 56, 15025-15029.

(17) Angelucci, C. A.; Varela, H.; Tremiliosi, G.; Gomes, J. F. The significance of non-covalent interactions on the electro-oxidation of alcohols on $\mathrm{Pt}$ and $\mathrm{Au}$ in alkaline media. Electrochem. Commun. 2013, 33, 10-13. 
(18) Singh, M. R.; Kwon, Y.; Lum, Y.; Ager, J. W.; Bell, A. T. Hydrolysis of Electrolyte Cations Enhances the Electrochemical Reduction of $\mathrm{CO} 2$ over Ag and Cu. J. Am. Chem. Soc. 2016, 138, 1300613012.

(19) Kristoffersen, H. H.; Chan, K.; Vegge, T.; Hansen, H. A. Energy-entropy competition in cation-hydroxyl interactions at the liquid water-Pt(111) interface. Chem Commun (Camb) 2020, 56, 427430.

(20) Suntivich, J.; Perry, E. E.; Gasteiger, H. A.; Shao-Horn, Y. The Influence of the Cation on the Oxygen Reduction and Evolution Activities of Oxide Surfaces in Alkaline Electrolyte. Electrocatalysis 2013, 4, 49-55.

(21) Norskov, J. K.; Rossmeisl, J.; Logadottir, A.; Lindqvist, L.; Kitchin, J. R.; Bligaard, T.; Jonsson, H. Origin of the overpotential for oxygen reduction at a fuel-cell cathode. J. Phys. Chem. B 2004, $108,17886-17892$.

(22) Keith, J. A.; Jerkiewicz, G.; Jacob, T. Theoretical investigations of the oxygen reduction reaction on $\mathrm{Pt}(111)$. Chemphyschem 2010, 11, 2779-2794.

(23) Calle-Vallejo, F.; Koper, M. T. M. First-principles computational electrochemistry: Achievements and challenges. Electrochim. Acta 2012, 84, 3-11.

(24) Rossmeisl, J.; Norskov, J. K.; Taylor, C. D.; Janik, M. J.; Neurock, M. Calculated phase diagrams for the electrochemical oxidation and reduction of water over Pt(111). J. Phys. Chem. B 2006, 110, 21833-21839.

(25) Sha, Y.; Yu, T. H.; Liu, Y.; Merinov, B. V.; Goddard, W. A. Theoretical Study of Solvent Effects on the Platinum-Catalyzed Oxygen Reduction Reaction. J. Phys. Chem. Lett. 2010, 1, 856-861.

(26) Sha, Y.; Yu, T. H.; Merinov, B. V.; Shirvanian, P.; Goddard, W. A. Oxygen Hydration Mechanism for the Oxygen Reduction Reaction at Pt and Pd Fuel Cell Catalysts. J. Phys. Chem. Lett. 2011, 2, 572-576.

(27) Tripkovic, V.; Vegge, T. Potential- and Rate-Determining Step for Oxygen Reduction on Pt(111). J. Phys. Chem. C 2017, 121, 26785-26793.

(28) Huang, J.; Zhang, J. B.; Eikerling, M. Unifying theoretical framework for deciphering the oxygen reduction reaction on platinum. Phys. Chem. Chem. Phys. 2018, 20, 11776-11786.

(29) Hyman, M. P.; Medlin, J. W. Mechanistic study of the electrochemical oxygen reduction reaction on $\mathrm{Pt}(111)$ using density functional theory. J. Phys. Chem. B 2006, 110, 15338-15344.

(30) Wasileski, S. A.; Janik, M. J. A first-principles study of molecular oxygen dissociation at an electrode surface: a comparison of potential variation and coadsorption effects. Phys. Chem. Chem. Phys. 2008, 10, 3613-3627.

(31) Wei, G. F.; Fang, Y. H.; Liu, Z. P. First Principles Tafel Kinetics for Resolving Key Parameters in Optimizing Oxygen Electrocatalytic Reduction Catalyst. J. Phys. Chem. C 2012, 116, 1269612705.

(32) Yeh, K. Y.; Janik, M. J. Density Functional Theory-Based Electrochemical Models for the Oxygen Reduction Reaction: Comparison of Modeling Approaches for Electric Field and Solvent Effects. J. Comput. Chem. 2011, 32, 3399-3408.

(33) He, Z. D.; Hanselman, S.; Chen, Y. X.; Koper, M. T. M.; Calle-Vallejo, F. Importance of Solvation for the Accurate Prediction of Oxygen Reduction Activities of Pt-Based Electrocatalysts. J. Phys. Chem. Lett. 2017, 8, 2243-2246.

(34) Calle-Vallejo, F.; de Morais, R. F.; Illas, F.; Loffreda, D.; Sautet, P. Affordable Estimation of Solvation Contributions to the Adsorption Energies of Oxygenates on Metal Nanoparticles. J. Phys. Chem. C 2019, 123, 5578-5582.

(35) Zhang, Q.; Asthagiri, A. Solvation effects on DFT predictions of ORR activity on metal surfaces. Catal. Today 2019, 323, 35-43. 
(36) Cheng, T.; Goddard, W. A.; An, Q.; Xiao, H.; Merinov, B.; Morozov, S. Mechanism and kinetics of the electrocatalytic reaction responsible for the high cost of hydrogen fuel cells. Phys. Chem. Chem. Phys. 2017, 19, 2666-2673.

(37) Li, Y. K.; Liu, Z. F. Modeling the effect of an anion on the free energy surfaces along the reaction pathways of oxygen reduction on Pt(111). Chem. Phys. Lett. 2019, 736, 6.

(38) Li, Y.; Liu, Z.-F. Solvated proton and the origin of the high onset overpotential in the oxygen reduction reaction on Pt(111). Phys. Chem. Chem. Phys. 2020.

(39) Liu, S. Z.; White, M. G.; Liu, P. Mechanism of Oxygen Reduction Reaction on Pt(111) in Alkaline Solution: Importance of Chemisorbed Water on Surface. J. Phys. Chem. C 2016, 120, 1528815298.

(40) Lima, F. H. B.; Zhang, J.; Shao, M. H.; Sasaki, K.; Vukmirovic, M. B.; Ticianelli, E. A.; Adzic, R. R. Catalytic Activity-d-Band Center Correlation for the O2Reduction Reaction on Platinum in Alkaline Solutions. The Journal of Physical Chemistry C 2007, 111, 404-410.

(41) Li, M. F.; Liao, L. W.; Yuan, D. F.; Mei, D.; Chen, Y.-X. pH effect on oxygen reduction reaction at $\mathrm{Pt}(111)$ electrode. Electrochim. Acta 2013, 110, 780-789.

(42) Rizo, R.; Herrero, E.; Feliu, J. M. Oxygen reduction reaction on stepped platinum surfaces in alkaline media. Phys. Chem. Chem. Phys. 2013, 15, 15416-15425.

(43) Tidswell, I. M.; Markovic, N. M.; Ross, P. N. POTENTIAL-DEPENDENT SURFACESTRUCTURE OF THE PT(111)VERTICAL-BAR-ELECTROLYTE INTERFACE. J. Electroanal. Chem. 1994, 376, 119-126.

(44) Tripkovic, A. V.; Popovic, K. D.; Lovic, J. D. A time effect in the early stages of a surface oxidation of a Pt(111) plane in alkaline solution. J. Serb. Chem. Soc. 2001, 66, 825-833.

(45) Gomez-Marin, A. M.; Rizo, R.; Feliu, J. M. Oxygen reduction reaction at Pt single crystals: a critical overview. Catalysis Science \& Technology 2014, 4, 1685-1698.

(46) Linstrom, P. J.; Mallard, W. G. The NIST Chemistry WebBook: A chemical data resource on the internet. J. Chem. Eng. Data 2001, 46, 1059-1063.

(47) Kaack, M.; Fick, D. Determination of the work functions of Pt(111) and $\operatorname{Ir}(111)$ beyond 1100 K surface temperature. Surface Science 1995, 342, 111-118.

(48) Pinto, L. M.; Quaino, P.; Arce, M. D.; Santos, E.; Schmickler, W. Electrochemical adsorption of $\mathrm{OH}$ on $\mathrm{Pt}(111)$ in alkaline solutions: combining DFT and molecular dynamics. Chemphyschem 2014, 15, 2003-2009.

(49) Lin, R.-J.; Quoc Chinh, N.; Ong, Y.-S.; Takahashi, K.; Kuo, J.-L. Temperature dependent structural variations of $\mathrm{OH}-(\mathrm{H} 2 \mathrm{O})(\mathrm{n}), \mathrm{n}=4-7$ : effects on vibrational and photoelectron spectra. Phys. Chem. Chem. Phys. 2015, 17, 19162-19172.

(50) Winter, B.; Faubel, M.; Hertel, I. V.; Pettenkofer, C.; Bradforth, S. E.; Jagoda-Cwiklik, B.; Cwiklik, L.; Jungwirth, P. Electron binding energies of hydrated $\mathrm{H} 3 \mathrm{O}+$ and $\mathrm{OH}-$ : Photoelectron spectroscopy of aqueous acid and base solutions combined with electronic structure calculations. J. Am. Chem. Soc. 2006, 128, 3864-3865.

(51) Bondarenko, A. S.; Stephens, I. E.; Hansen, H. A.; Perez-Alonso, F. J.; Tripkovic, V.; Johansson, T. P.; Rossmeisl, J.; Norskov, J. K.; Chorkendorff, I. The Pt(111)/electrolyte interface under oxygen reduction reaction conditions: an electrochemical impedance spectroscopy study. Langmuir : the ACS journal of surfaces and colloids 2011, 27, 2058-2066.

(52) Bratsch, S. G. Standard Electrode Potentials and Temperature Coefficients in Water at 298.15 K. Journal of Physical and Chemical Reference Data 1989, 18, 1-21.

(53) Taylor, C. D.; Wasileski, S. A.; Filhol, J. S.; Neurock, M. First principles reaction modeling of the electrochemical interface: Consideration and calculation of a tunable surface potential from atomic and electronic structure. Phys. Rev. B 2006, 73, 16. 
(54) Filhol, J. S.; Neurock, M. Elucidation of the electrochemical activation of water over Pd by first principles. Angew. Chem. Int. Ed. Engl. 2006, 45, 402-406.

(55) Huang, J.; Malek, A.; Zhang, J. B.; Eikerling, M. H. Non-monotonic Surface Charging Behavior of Platinum: A Paradigm Change. J. Phys. Chem. C 2016, 120, 13587-13595.

(56) Huang, J.; Zhou, T.; Zhang, J. B.; Eikerling, M. Double layer of platinum electrodes: Nonmonotonic surface charging phenomena and negative double layer capacitance. J. Chem. Phys. 2018, $148,6$.

(57) Garlyyev, B.; Xue, S.; Watzele, S.; Scieszka, D.; Bandarenka, A. S. Influence of the Nature of the Alkali Metal Cations on the Electrical Double-Layer Capacitance of Model Pt(111) and Au(111) Electrodes. J. Phys. Chem. Lett. 2018, 9, 1927-1930.

(58) Robertson, W. H.; Diken, E. G.; Price, E. A.; Shin, J. W.; Johnson, M. A. Spectroscopic determination of the $\mathrm{OH}$ - solvation shell in the $\mathrm{OH}$-center $\operatorname{dot}(\mathrm{H} 2 \mathrm{O})(\mathrm{n})$ clusters. Science 2003, 299, 13671372.

(59) Xantheas, S. S. Theoretical Study of Hydroxide Ion-Water Clusters. J. Am. Chem. Soc. $1995,117,10373-10380$.

(60) Bucko, T. Ab initio calculations of free-energy reaction barriers. Journal of physics. Condensed matter : an Institute of Physics journal 2008, 20, 064211.

(61) Zhao, X.; Liu, Y. Unveiling the Active Structure of Single Nickel Atom Catalysis: Critical Roles of Charge Capacity and Hydrogen Bonding. J Am Chem Soc 2020, 142, 5773-5777.

(62) Kristoffersen, H. H.; Vegge, T.; Hansen, H. A. OH formation and H-2 adsorption at the liquid water-Pt(111) interface. Chemical Science 2018, 9.

(63) Kresse, G.; Hafner, J. Ab initio molecular-dynamics simulation of the liquid-metalamorphous-semiconductor transition in germanium. Phys. Rev. B Condens. Matter Mater. Phys. 1994, 49, 14251-14269.

(64) Kresse, G.; Furthmüller, J. Efficiency of ab-initio total energy calculations for metals and semiconductors using a plane-wave basis set. Computational Materials Science 1996, 6, 15-50.

(65) Perdew, J. P.; Burke, K.; Ernzerhof, M. Generalized gradient approximation made simple. Phys. Rev. Lett. 1996, 77, 3865-3868.

(66) Grimme, S.; Antony, J.; Ehrlich, S.; Krieg, H. A consistent and accurate ab initio parametrization of density functional dispersion correction (DFT-D) for the 94 elements H-Pu. J. Chem. Phys. 2010, 132, 154104.

(67) Kresse, G.; Joubert, D. From ultrasoft pseudopotentials to the projector augmentedwave method. Phys. Rev. B 1999, 59, 1758-1775.

(68) Neugebauer, J.; Scheffler, M. Adsorbate-substrate and adsorbate-adsorbate interactions of $\mathrm{Na}$ and $\mathrm{K}$ adlayers on Al(111). Phys. Rev. B Condens. Matter Mater. Phys. 1992, 46, 16067-16080.

(69) Laio, A.; Gervasio, F. L. Metadynamics: a method to simulate rare events and reconstruct the free energy in biophysics, chemistry and material science. Rep. Prog. Phys. 2008, 71, 126601.

(70) Bucko, T. Ab initio calculations of free-energy reaction barriers. J. Phys.: Condens. Matter 2008, 20, 064211.

(71) Becke, A. D. A new mixing of Hartree-Fock and local density-functional theories. The Journal of Chemical Physics 1993, 98, 1372-1377.

(72) Lee, C.; Yang, W.; Parr, R. G. Development of the Colle-Salvetti correlation-energy formula into a functional of the electron density. Phys. Rev. B 1988, 37, 785-789.

(73) Wiberg, K. B. Basis set effects on calculated geometries: 6-311++G** vs. aug-cc-pVDZ. J Comput Chem 2004, 25, 1342-1346.

(74) Frisch, M. J.; Trucks, G. W.; Schlegel, H. B.; Scuseria, G. E.; Robb, M. A.; Cheeseman, J. R.; Scalmani, G.; Barone, V.; Mennucci, B.; Petersson, G. A.; Nakatsuji, H.; Caricato, M.; Li, X.; Hratchian, H. 
P.; Izmaylov, A. F.; Bloino, J.; Zheng, G.; Sonnenberg, J. L.; Hada, M.; Ehara, M.; Toyota, K.; Fukuda, R.; Hasegawa, J.; Ishida, M.; Nakajima, T.; Honda, Y.; Kitao, O.; Nakai, H.; Vreven, T.; Montgomery, J. A.; Peralta, J. E.; Ogliaro, F.; Bearpark, M.; Heyd, J. J.; Brothers, E.; Kudin, K. N.; Staroverov, V. N.; Kobayashi, R.; Normand, J.; Raghavachari, K.; Rendell, A.; Burant, J. C.; Iyengar, S. S.; Tomasi, J.; Cossi, M.; Rega, N.; Millam, J. M.; Klene, M.; Knox, J. E.; Cross, J. B.; Bakken, V.; Adamo, C.; Jaramillo, J.; Gomperts, R.; Stratmann, R. E.; Yazyev, O.; Austin, A. J.; Cammi, R.; Pomelli, C.; Ochterski, J. W.; Martin, R. L.; Morokuma, K.; Zakrzewski, V. G.; Voth, G. A.; Salvador, P.; Dannenberg, J. J.; Dapprich, S.; Daniels, A. D.; Farkas; Foresman, J. B.; Ortiz, J. V.; Cioslowski, J.; Fox, D. J.: Gaussian 09 Revision D.01. 2009.

(75) Grimme, S.; Antony, J.; Ehrlich, S.; Krieg, H. A consistent and accurate ab initio parametrization of density functional dispersion correction (DFT-D) for the 94 elements H-Pu. J. Chem.

Phys. 2010, 132, 154104. 